\title{
Cost-benefit analysis of smoking in Latvia
}

\author{
Anita Kokarevica ${ }^{1}$ and Anastasija Ludzeniece ${ }^{2}$ \\ ${ }^{1}$ Rīga Stradinsš University, Riga, Latvia \\ ${ }^{2}$ SIA CETERA, Riga, Latvia
}

\begin{abstract}
One of 3 persons in Latvia is a smoker. Smoking has been proved to be linked to different cancer, cardiovascular and respiratory diseases. The overall purpose of the study addresses smoking as a cost-benefit subject in Latvian state economy. A model to perform evidence-based cost-benefit analysis (CBA) was developed highlighting direct and indirect costs borne by the state, smokers and second-hand smokers. The paper envisages the approach to building the model. As the first study on economic impact of smoking in Latvia, the CBA results demonstrate substantial excess of financial benefits from smoking citizens in Latvia. Authors discuss the smoking attributable fraction (SAF) eligibility and needs in data to discover the full impact of smoking on health and non-health aspects.
\end{abstract}

Key words: CBA, smoking, costs, benefits, SAF.

\section{Introduction}

Every $4^{\text {th }}$ person over 15 is a smoker in the European Union [2]. In Latvia, the issue is even bigger - every $3^{\text {rd }}$ person smokes on daily basis [1]. Smoking as a habit of citizens makes a sound impact on Gross Domestic Product in two polar ways: state budget income and expense. While regulating cigarette consumption with excise tax, the income budget grows. Simultaneously state compensates a notable part of healthcare costs to its citizens who experience smoking affected diseases. Is smoking the cost or the benefit? To address the question, a cost-benefit analysis (CBA) should be performed. Historically CBA covered analysis of investment projects and programs in infrastructure. By increasing the social investment portfolio of the European Union, the cost-benefit analysis methodology was enhanced to be applicable to the specifics of healthcare, education and social care sectors. Both, in infrastructure and social domain, CBA implies discounting of the cash flow and comparing intervene investments and operating costs with the benefits of achieved intervention goals.

The aim of the paper is to present the approach and the results of the analysis of Latvian state costs and benefits of cigarette smoking. The paper describes the CBA model, the limitations and assumptions for CBA calculation and discusses the results of the analysis performed.

\section{Material and methods}

In order to perform the cost-benefit analysis, the model for assessing the impact of tobacco use on the socio-economic development of Latvia has been developed. The structure of the model implies current world practice on methodology applied in other countries and is limited with availability of statistical data. The model construction approach is demonstrated in Fig. 1. 
1. Defining theoretical frame of the model

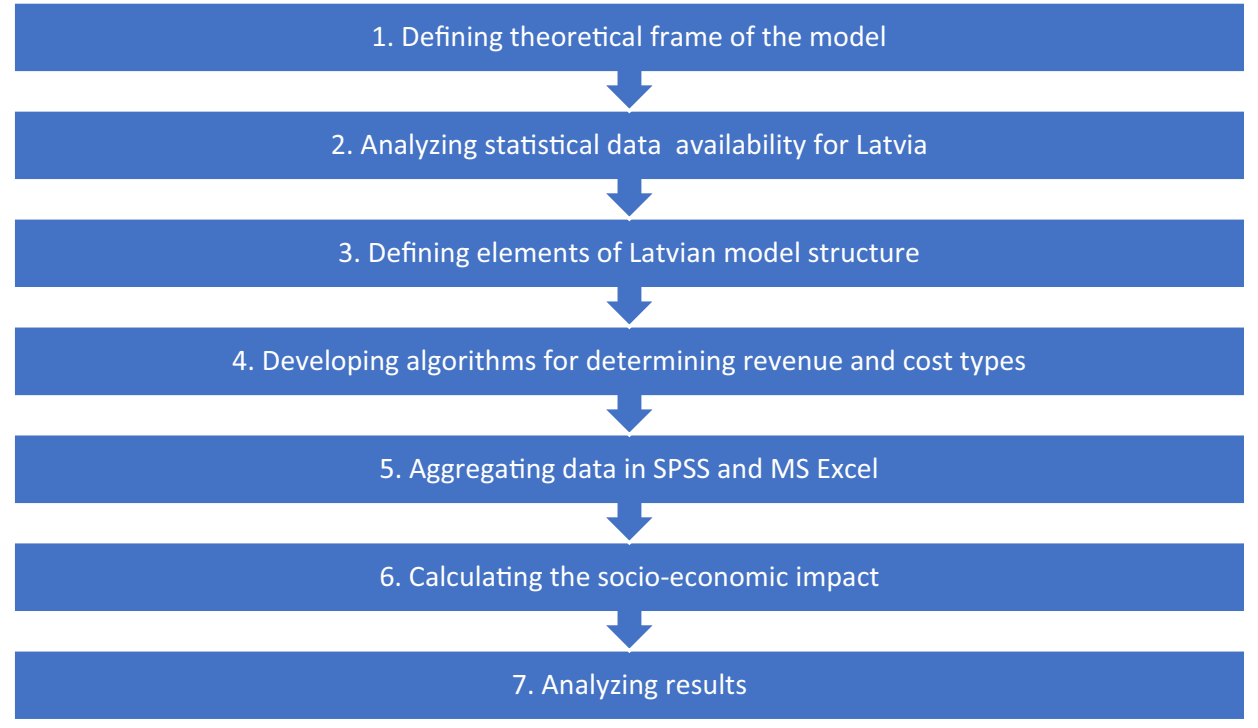

Fig. 1. The model development approach.

The key principle of the Latvian model is the value of lost lives due to smoking. It is based on WHO proposed Excess Cost Approach [1]. The model analyzes long-term expenses applying Annual Cost Approach. The model addresses four cost factors:

1. Provision of healthcare services to smokers (in terms of smoking related diseases);

2. Consumption of services due to smoking;

3. Morbidity (lost productivity due to smoking);

4. Premature mortality among smokers.

The impact assessment model includes both direct and indirect costs, thus drawing conclusions about the visible and hidden losses of the society from the long-term use of tobacco. The cost directness criterion can be determined by the existence of real expenditures: spending on the purchase of goods and services constitutes direct costs; the source of indirect costs is the potential loss of income. In other words, indirect costs consist of income that a person could have earned if smoking had not affected the person through disability or premature death. To determine the indirect costs authors applied the Human Capital Approach [6].

The socio-economic model focuses on the state income and losses, and it includes some of the smokers' borne costs as represented in Fig. 2.

Authors carried out an expert survey as well as analysis of public data and approached public administration bodies to gather data about smoking impacts and costs.

Recent epidemiological studies have evidenced that not only numerous forms of cancer diseases appear due to smoking, but also cardiovascular diseases, chronic obstructive pulmonary disease and acute respiratory illnesses [3]. In terms of statistical data availability, the following diseases have been included in the impact assessment in Latvian model (according to International Classification of Diseases, ICD-10 [4]):

1. Neoplasms:

a. Malignant neoplasms of lip, oral cavity and pharynx (C00-C14)

b. Malignant neoplasm of oesophagus (C15) 


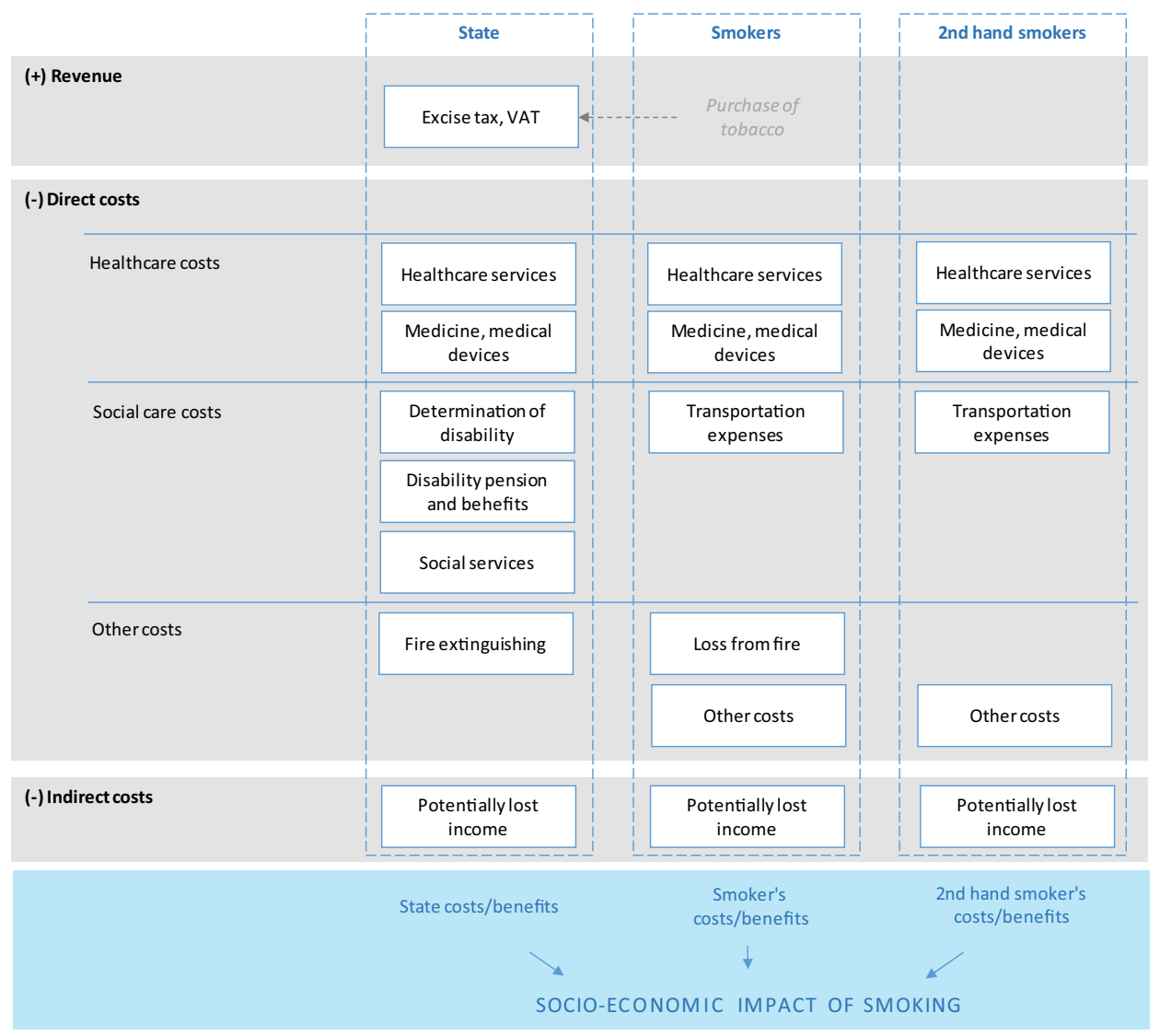

Fig. 2. Socio-economic assessment model of impact of smoking.

c. Malignant neoplasm of stomach (C16)

d. Malignant neoplasm of pancreas (C25)

e. Malignant neoplasm of larynx (C32)

f. Malignant neoplasm of trachea (C33)

g. Malignant neoplasm of bronchus and lung (C34)

h. Malignant neoplasm of cervix uteri (C53)

i. Malignant neoplasm of kidney, except renal pelvis (C64)

j. Malignant neoplasm of renal pelvis (C65)

k. Malignant neoplasm of bladder (C67)

1. Myeloid leukemia (C92)

2. Diseases of circulatory system:

a. Ischaemic heart diseases (I20-I25)

b. Cerebro-vascular diseases (I60-I69)

c. Atherosclerosis (I70)

d. Aortic aneurysm and dissection (I71)

e. Other peripheral vascular diseases (I73)

f. Arterial embolism and thrombosis (I74) 
3. Diseases of the respiratory system:

a. Simple and mucus-purulent chronic bronchitis (J41)

b. Unspecified chronic bronchitis (J42)

c. Emphysema (J43)

d. Other chronic obstructive pulmonary disease (J44)

Another important input to calculate smoking impact is SAF calculation. Smoking attributable fraction is a central measure that determines the impact of smoking on any instance. Rosen explains SAF with the following formula:

$$
S A F=\frac{A}{A+B+C},
$$

where

A - number of smokers within the population with diagnosed $\mathrm{X}$ disease due to smoking;

$\mathrm{B}$ - number of smokers within the population with diagnosed $\mathrm{X}$ disease due to other reasons (not smoking);

$\mathrm{C}$ - number of non-smokers with diagnosed $\mathrm{X}$ disease within the population.

Assuming $\mathrm{T}$ is the total number of persons with diagnosed $\mathrm{X}$ disease, the formula can be simplified and explained as follows:

$$
A F=\frac{A}{T}
$$

Through this formula, SAF can be defined as the number of persons with diagnosed $\mathrm{X}$ disease due to smoking divided by the total number of persons with diagnosed $\mathrm{X}$ disease [8].

In practice, SAF determination in a certain country is an extremely time and resource requiring intensive activity. In order to determine the relative risk of smoking, causing a certain disease, comparing it with the illness of non-smokers, authors of numerous epidemiological studies addressed the necessity to collect individual data within a long period. Then it can be empirically and statistically inferred from the degree of illness and smoking relationship between different profiles (age, gender, and other parameters). The 2009 GHK study, commissioned by the EU, summarizing the results of current economic studies, concluded that all previous studies (at least until 2009) were based on the US study CPSII (US Surgeon General) and used standardized SAF indicators from this study [7, 9]. Equivalent scale study in 2010-2014 was carried out in China, where smoking annually kills a significant part of the country's economically active population [5]. Authors of economic impact calculations for smoking in different countries similarly conclude that in order to empirically and statistically verify the link between smoking and diseases in other geopolitical regions with different social, ecological, and other factors, long-term studies of similar scale should be carried out [3]. Authors applied the SAF measurements determined by Sir Richard Peto and his team, which is also based on US study CPSII.

\section{Results}

The cost and benefit cash flow for smoking as presented in Appendix 1 depicts gradual rise of excise tax revenues - 166.2 million euro in 2014 and $7 \%$ annual growth further. Assuming the dynamics of income rise will drop to $3 \%$ annually, within next 15 years state will collect about 2.5 billion euro (discounted value) from the restrictions in tobacco production and trade.

Smoking linked disease costs compound direct costs. These are out- and inpatient service expenses and medicines, other non-healthcare expenses. Consumption of outpatient and inpatient services in Riga and rural areas is very similar. Indirect costs include productivity 
loss in case of work ability loss and years lost in case of mortality. In 2014, state budget expenses of 79.3 million euro were assigned to healthcare services for smokers in Latvia. Applying SAF rate of $14.85 \%$, indirect costs related to productivity loss due to work ability loss comprised 41 million euro in 2014. Mortality of smokers reflects the number of years they could have worked if had not smoked. Based on statistical data of 2014, smokers trigger 9.8 million euro in indirect costs.

To summarize the CBA results it is important to point out that the net present value of state costs and benefits within 15-year-period comprises 1.46bln euro. It means that Latvian state gains financial benefits from smoking citizens, if the level of healthcare, social care and other services to smokers remains at the recent mark. The cost-benefit ratio reaches 2.35, i.e. benefits significantly exceed the related costs.

\section{Discussion}

This paper shortly depicts the initial results of cost-benefit analysis of smoking in Latvia. The methodology and the results gained raise several questions.

Firstly, the SAF applied values were derived from US statistics about smokers' health. As the economic, social and environmental issues differ in the US and Latvia, the relative risk of certain diseases may differ substantially. Thus, the real economic impact of smokers can both increase and decrease significantly. Nevertheless, the actual CBA numbers trigger a sharp need to start gathering individual data on smokers' health dynamics in Latvia to draw realistic conclusions about the smokers' impact on socio-economic development of Latvia.

Secondly, the list of costs related to smokers' treatment requires certain additional positions like homecare, alternative healthcare services, family expenditures to sustain smoke-free environment, employers' expenditures to train new employees in case of smokers' illness. Moreover, the administrative burden of smoking control, tax collection, legislation and monitoring should be estimated and analyzed within the further research on economic impact of smoking.

\section{Conclusions}

The analysis of state costs and benefits demonstrates substantial excess of state benefits resulting from tobacco smoking, although state regulation and control activities are in force, and state healthcare system provides outpatient and inpatient services to smokers and secondhand smokers. There is a wide opportunity to tighten the state regulation and review state funding to compensate smoking consequences.

\section{References}

[1] World Health Organization, Economics of tobacco toolkit: assessment of the economic costs of smoking (2011). Retrieved from www.who.int

[2] Eurostat, Tobacco consumption: 1 in every 4 persons aged 15 or over in the European Union is a smoker (2016). Retrieved from https://ec.europa.eu/eurostat/documents/ 2995521/7762296/3-07122016-AP-EN.pdf/e6cf7fd2-06a5-45ba-8385-991bccef54fd

[3] GHK, A study on liability and the health costs of smoking (2012). Retrieved from www.ghkint.com

[4] International Classification of Diseases, ICD-10 (2016). Retrieved from https://icd.who.int/browse10/2016/en\#/J40-J47

[5] W. Li, G. Jiang, D. Wang, H. Zhang, Z. Xu, Y. Zhang et al, Smoking and Mortality in Tianjin, China: A Death Registry-Based Case-Control Study, 
2010-2014. Preventing Chronic Disease 15, 170577 (2018). Retrieved from https://doi.org/10.5888/pcd15.170577

[6] W. Max, D.P. Rice, H.-Y. Sung, M. Michel, Valuing Human Life: Estimating the Present Value of Lifetime Earnings, 2000 (2004). Retrieved from https://escholarship.org/uc/item/82d0550k\#supplemental

[7] R. Peto, A.D. Lopez, H. Pan, J. Boreham, M. Thun, Mortality from smoking in developed countries 1950-2020 (2006). Retrieved from www.deathsfromsmoking.net

[8] L. Rosen, An intuitive approach to understanding the attributable fraction of disease due to a risk factor: the case of smoking, International Journal of Environmental Research and Public Health 10(7), 2932-2943 (2013). Retrieved from https://doi.org/10.3390/ijerph10072932

[9] United States. Public Health Service. Office of the Surgeon General, How tobacco smoke causes disease: the biology and behavioral basis for smoking-attributable disease: a report of the Surgeon General. U.S. Dept. of Health and Human Services, Public Health Service, Office of the Surgeon General (2010) 


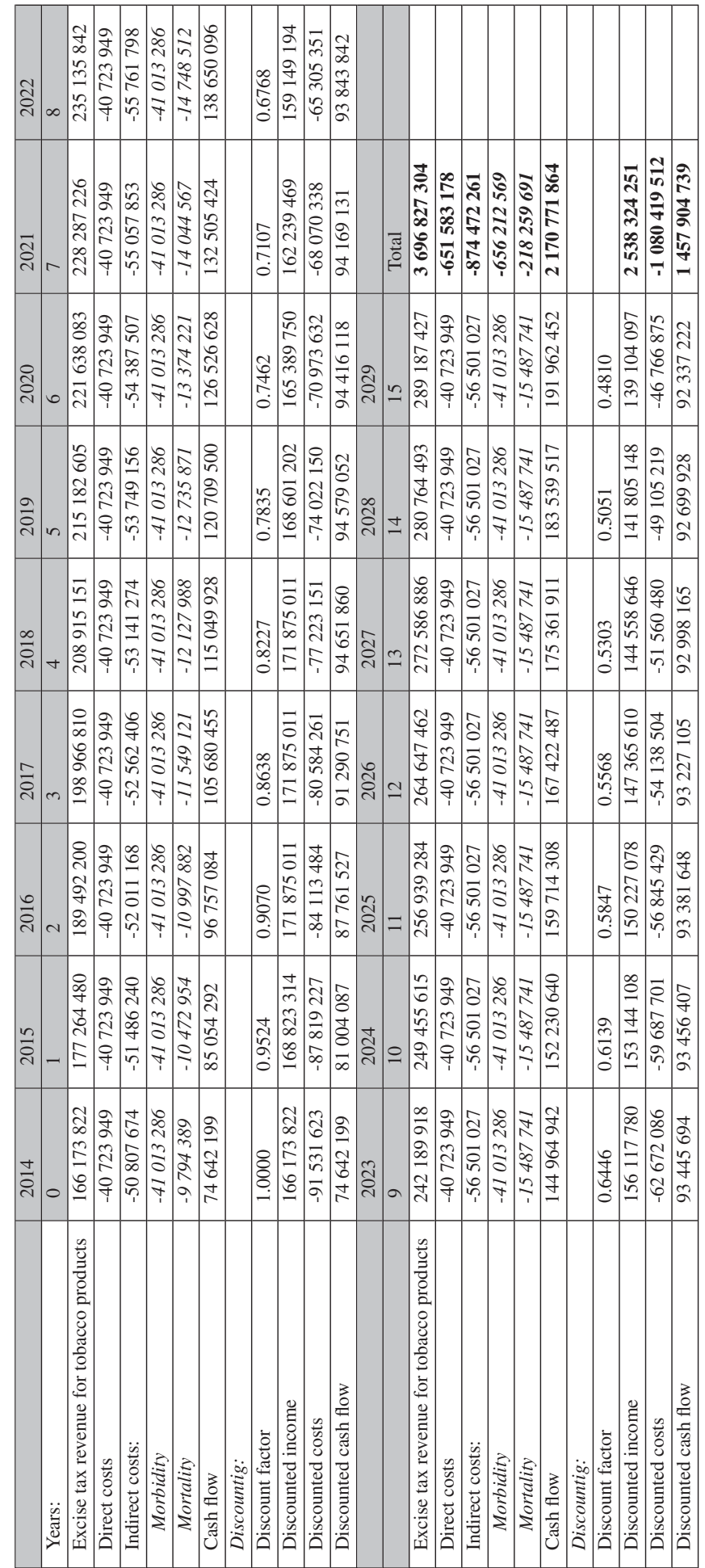

